\title{
USING BLENDED LEARNING MODEL IN IMPROVING SELF-STUDY COMPETENCE IN PHYSICS SUBJECT OF HIGH SCHOOL STUDENTS
}

\author{
Ngoc Thi Lan Nguyen ${ }^{1,+}$, \\ Hien Thi Thu Le', \\ Nhi Thi Nguyen', \\ Tuan Minh Dang ${ }^{2}$
}

\section{Article History}

Received: November 11, 2019

Accepted: February 26, 2020

Published: March 30, 2020

\section{Keywords}

Self-study competency, improving self-study

competence, B-learning, Physics teaching, high school students

\author{
${ }^{1}$ Hue University's College of Education, Vietnam; \\ ${ }^{2}$ VNU University of Education, Vietnam National University; \\ ${ }^{3}$ Vinh University, Vietnam \\ ${ }^{+}$Corresponding author • Email: lanngoc2806@gmail.com
}

\section{INTRODUCTION}

Blended learning (B-learning) is one of the forms of learning that attracts the attention of educators. B-learning is a significant step forward in teaching, helping to create an interactive environment, creating a convenient way of communication between teachers and students (Tran Trung \& Nguyen Van Hong, 2011). B-learning helps teachers organize well the self-study activities of students with the combination of self-study in class with face-to-face and home-learning with online learning (Alqarni, 2018).

Organizing students' self-study activities is an important issue in the teaching process, thereby improving students' self-study ability so that students can acquire knowledge without the support of teachers. It can be seen that B-learning brings many advantages for teaching in general and self-study activities in particular (Allan, 2018). In Physics teaching, B-learning can support students' self-study activities better than the traditional teaching model in all forms of self-study (including self-study in class with the guidance of teachers, self-study completely at home).

On the basis of analyzing the advantages of B-learning model, the article presents the results of improving the ability of self-studying Physics at high schools in Vietnam in the form of B-learning.

\section{LITERATURE REVIEW}

\subsection{Studies on self-study competence and improving self-study competence}

Self-study is learner self-thinking and creating his or her own systematically oriented behaviors to achieve his or her own learning goals (Barry J. Zimmerman, 1990). Self-study from a social awareness perspective is considered the interaction between individuals, behaviors and the environment (Setyaningrum, 2019). Self-study is selfexploration, self-questioning, self-study to understand the problem, gain a deeper understanding, even understand differently by being creative, reaching an answer, a different conclusion (Thao, 2015; Jang, 1992; Yoda, Miyatake \& Matsushima, 1991).

Self-study competence is the ability to explore, understand and apply knowledge in a new or similar situation with high quality (Le Hien Duong, 2010). Self-study ability is expressed by the subject who correctly determines his/ her motivation for learning, has the ability to manage his or her own learning and has a positive attitude in activities to be able to work on his own, adjust their learning activities and assess their own learning results, so they can work independently and collaborate with others (Trinh Quoc Lap, 2003). Self-study competence is the ability to identify learning tasks voluntarily and proactively; self-set learning goals and strive to achieve them; have effective learning methods; adjust mistakes and limitations of themselves when performing learning tasks through self-evaluation or suggestions from teachers and friends; actively seek support when having difficulties in learning (Luong Viet Manh, 2015).

Self-study competence consists of 4 components and behavioral criteria are evaluated based on 4 levels of achievement (weak, moderate, fair, good) as follows (Tran Duc Khoan, 2016): 


\begin{tabular}{|c|c|}
\hline Competence's component & Criterion \\
\hline \multirow{4}{*}{$\begin{array}{l}\text { Identify learning goals } \\
\text { and tasks }\end{array}$} & Determine subject objectives voluntarily and proactively \\
\hline & Identify specifically learning tasks \\
\hline & Identify tasks that are appropriate to self abilities \\
\hline & The set task must ensure time to complete \\
\hline \multirow{11}{*}{$\begin{array}{l}\text { Capacity to plan learning, } \\
\text { and conduct learning } \\
\text { according to the plan }\end{array}$} & Make a self-study plan with clear, specific goals \\
\hline & Created plans ensure regular self-assessment \\
\hline & Search and use materials for the subject \\
\hline & Analyze, synthesize, generalize learning content \\
\hline & Explore, expand and deepen subject knowledge \\
\hline & Find the relationship between the given and the sought in the problem \\
\hline & Detect and present course questions \\
\hline & Argue, rebuttal and defend individual or group opinions \\
\hline & Coordinate learning methods \\
\hline & Collaborative sharing in learning \\
\hline & Complete the learning mission \\
\hline \multirow{3}{*}{$\begin{array}{l}\text { Applying knowledge } \\
\text { in learning and practice }\end{array}$} & Apply the knowledge of related subjects to solve the subjects' problems \\
\hline & Apply theoretical knowledge to solve specific exercises \\
\hline & Apply knowledge to explain Physics phenomena in reality \\
\hline \multirow{8}{*}{$\begin{array}{l}\text { Self-assessment and } \\
\text { adjustment of learning }\end{array}$} & Check academic results through the self-test \\
\hline & Evaluate academic results against the set goals \\
\hline & Evaluate academic performance through teacher comments \\
\hline & Evaluate learning results through feedback of other students in the group \\
\hline & Promote strengths in learning. \\
\hline & Identify and correct errors, overcome difficulties in learning \\
\hline & Draw comments on academic ability. \\
\hline & Adjust self-study plan \\
\hline
\end{tabular}

Cultivating self-study competence for students is an important and indispensable task for teachers because schools mainly provide sufficient background knowledge for students and students need self-study capacity for a lifetime to be able to teach themselves research to discover other knowledge that schools do not teach (Trinh Quoc Lap, 2003). In Vietnam, many scientists have studied the development of self-study competence including studies showing measures to foster self-study competence of students through the design of study worksheet and revision review for Physics subject (Luong Viet Manh, 2015). It is also possible to carry out the activity of developing selfstudying competence for students in the form of developing self-study materials in Physics, including digitizing selfstudy materials on the internet so that students can have more self-study materials number format (Tran Duc Khoan, 2016). Improving scientific research competence can also be done through scientific research activities and seminars in teaching (Le Hien Duong, 2010).

With the development of the industrial revolution 4.0, information technology develops and becomes a special tool to support teaching as well as create a good environment for the development of students' self-study competence. A number of studies have shown that improving self-study competence of students does not only need to be done with measures outside the classroom but also can be integrated into the classroom teaching classes with the help of computers (Le Thanh Huy \& Nguyen Thi Bich Hoa, 2018), or it is possible to develop self-study competence for students through E-learning (Nguyen Van Hien, 2016). However, improving self-study competence for students in the traditional form or E-learning format has advantages and disadvantages. Therefore, improving self-study competence for high school students using the B-learning model will overcome the disadvantages of both forms and is still a gap in research in Vietnam.

\subsection{Studies of combined teaching}

Blended learning (B-learning) is a teaching method of interest. Scientists think this form of integrated learning demonstrates the use of technology in traditional teaching to facilitate teaching and learning, a combination of 
pedagogical methods used to create optimal learning results; a mixture of protocols used to achieve teachers' educational goals and student learning outcomes (Welker \& Berardino, 2005).

According to Allan (2018), blended learning involves a combination of direct activities with E-learning and often involves the use of internet-based tools, including: chat rooms, discussion groups, podcasts and self-assessment tools, to support a traditional course. Blended learning is becoming a regular training method because individuals are using a combination of face-to-face and online training even when simply providing e-mail support or access into additional learning resources.

Many studies have been done to determine the effectiveness of B-learning in enhancing the success of school learning. Notably, most surveys show that B-learning is effective in promoting intensive education among learners (Alqarni, 2018).

B-learning practices are being accepted and built into the key processes in education and training processes around the world. Researchers have shown that B-learning method brings higher learning efficiency than traditional teaching method and computer-based teaching method (Yang et al., 2019).

B-learning has the following characteristics: not limited by space and time, attractiveness, updating, flexibility, random access, cooperative and coordinated, save time, widely dispersed at low cost (Tran Trung \& Nguyen Van Hong, 2011).

Forms of self-study support for students under B-learning include: 1) Teachers organize traditional teaching in class, E-learning is only a reference; 2) Teachers design, package and transmit learning content, create forums, guide self-study on E-learning system in parallel with traditional classroom learning; 3) Teachers require students to participate in self-study of a unit of knowledge online directly related to the lesson being taught; 4) Students completely self-study a lesson content on E-learning system.

\section{METHODS AND RESULTS}

\subsection{Methods}

The research uses theoretical research methods in combination with qualitative research methods to analyze and produce research results. The study is conducted through an overview of domestic and foreign documents to give the concept and theoretical framework for improving self-study competence of students according to the B-learning model; At the same time, designing the E-learning system of Physics, putting it into practice and using case studies to monitor and evaluate students' self-study ability on the selected sample of 255 students of grade 11 belonging to Huong Hoa high school and Dakrong high school, Quang Tri province in the period from December 2018 to April 2019.

\subsection{Results}

\subsubsection{Building E-learning system of General Physics}

The research results have designed E-learning system for Physics teaching at: http://online.vatlysuphamhue.com with functions including synchronized lectures; electronic exercises; assessment; data; forum.

Each student will register as a member to participate in the class according to the protocol:

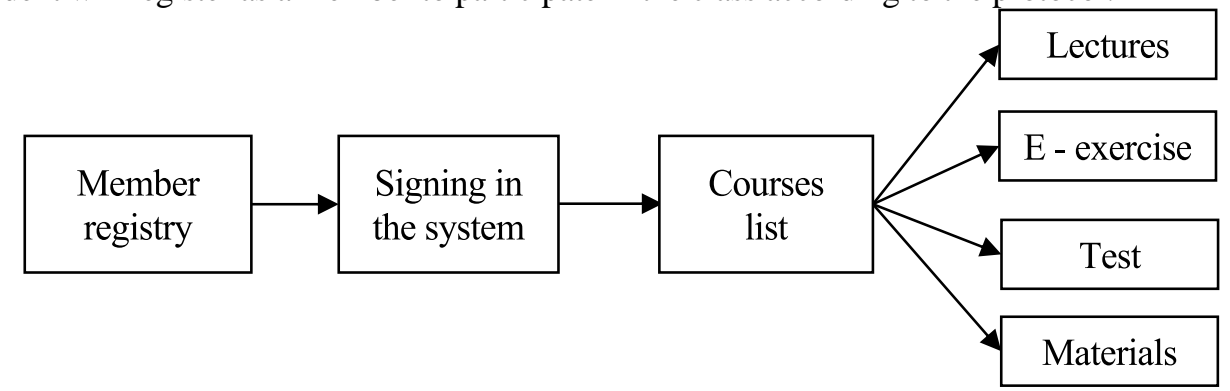

E-learning system includes:

Figure 1. Class registering protocol

+ Synchronized electronic lectures: Synchronized electronic lectures with information-rich content should create a visual, vivid and attractive way and fully transmit knowledge to students. Because the lecture is synchronized between the video recording the teacher giving the lecture and the information displayed on the PowerPoint screen, students feel like they are listening to the actual lecture teacher and can adjust to fast, slow, temporary stop or go directly to the topic of interest.

+ Electronic exercises Physics: Students can do the exercises by their own choice with different difficulty levels. Through solving exercises, students are trained in applying the knowledge they have learned to solve learning tasks. 
Besides electronic exercises are accompanied with solutions and instructions; Therefore, students can do the exercises themselves without necessarily having the guidance of teachers.

+ Online checking about Physics knowledge: The exam bank has a database structure designed to be flexible so that it can give the exam questions with different difficulty levels, scoring other assessed questions, even the subquestion. It is possible to create exam questions and tests with a combined knowledge of various parts of the subject. The test consists of many parts. For each section, we have the number of questions for each section and the score for each section. These are useful and detailed options for teachers to present a test that wants to fully assess students' competence.

+ Electronic materials supporting Physics subject: On the E-learning page, there are electronic textbooks and materials for the reference, learning, research of teachers and students. Advantages in searching and exchanging information among members of Physics E-learning system.

+ Exchange forum: On the system, there is a forum design so that teachers and students or between students can exchange and discuss with each other to help the learning process better.

\subsubsection{Improving self-study competence of student by B-learning in teaching Physics}

With the characteristics and levels of self-study competence as analyzed along with the advantages of the B-learning model, it is possible to improve the self-study competence of students in Physics teaching under the B-learning model.

After having an E-learning system, based on the theoretical model of improving self-study competence according to B-learning, the following measures can be implemented to improve the competence of general students in Physics teaching:

Measure 1: Improving the skills of self-exploring materials and exchanging on the forum of Physics E-learning system to perform the tasks assigned by the teacher:

In order to develop students' self-study competence, the most important issue is to help students find their own resources to research to help implement the study plan and tasks. Physics E-learning system is a repository of physics, connected to libraries, websites so that students can use keywords to search for available resources on the system as well as from websites linked to the system. In addition, on the system that has available testing software, teachers can ask students to perform virtual experiments on their own or design their own virtual experiments on the system in addition to performing practical experiments available during school hours.

Doing this will help students set plans, tasks, self-search data to perform tasks and regularly feedback the results for teachers and students on the forum for teachers to make timely comments and adjust students' self-study process.

The process of instructing students to search for information, documents and exchange on E-learning system as follows:

Step 1: $\log$ in to the website with the domain name provided; Step 2: Search documents related to the content or topic of interest; Step 3: Classify documents to file a search topic; Step 4: Exploiting information; Step 5: Summarize of information extraction process.

Measure 2: Students self-study electronic lessons and exercises on the E-learning system of Physics

In teaching with B-learning model, teachers can choose to teach only a few lessons or a part of knowledge in one lesson, the remaining lessons require students to self-study at home on Physics E-learning system by synchronized lectures. Teachers can notify the plan in advance, students base on their own study plan, read textbooks, search for additional reading materials; At the same time, self-study through teaching videos of teachers in the classroom, selfcarrying out online exercises. Core issues of self-study by students will be discussed in class at the following class. Besides, students themselves perform electronic exercises on the system to develop their self-review and consolidation capacity.

With this way of learning, B-learning Physics helps to shorten the time of lectures in the classroom, spend more time for students in group activities, discuss the problem of self-study and do the exercises on the system themselves. This way of assigning tasks helps students nurture their ability to plan for self-study, search for documents, identify learning goals and self-solve assigned tasks. Thereby, gradually improving students self-study competence helps develop students' self-study competence.

Measure 3: Students perform online self-examination and self-assessment

To evaluate the results of students' online self-study, teachers need to improve students' skills of online selfassessment and self-assessment. To do this, teachers need to design a system of questions, essay exercises, multiplechoice exercises with the goal of helping learners to self-assess their own learning results to guide learning activities. 
The purpose of building a system of objective tests is to help learners to formulate the ability to think quickly and accurately in choosing the answer options for each question. This approach has the advantage of allowing us to immediately assess the learning results of students, each student can also check and assess their own learning results very quickly, thereby fostering success. Self-assessment factor is the highest component of students' self-study ability. 3.2.3. Experimental results in improving self-study competence for high school students by B-learning model

Organizing the application of the proposed measures in the process of teaching the subject Geometrical Optics for 255 students of grade 11 of Huong Hoa high school and Dakrong high school in Quang Tri province in the second semester in school year 2018-2019, the following results are obtained:

Through monitoring the E-learning system of Physics, students' self-study time in the system increased significantly, the majority of students completed the tasks assigned by the teachers. The atmosphere of the class was lively. Students participated actively in discussions about self-study tasks that were performed at home. In the forum, there are often students discussing exercises and tests. The questioning of teachers during the process of self-study is done regularly; the cooperation between teachers and students takes place closely throughout the process of students performing self-study tasks and including the time in class.

Besides, observing and monitoring 3 cases during the experiment, the following results are obtained:

(1). Tran Van X, born on August 22, 2002 is a good student with good academic results, is a positive student according to the evaluation of the Physics teacher. The final score of the first semester, Physics subject of $\mathrm{X}$ is 8.5.

(2) Truong Le V, born on July 12, 2002 is a student with good academic performance, according to the evaluation of the Physics teacher, during class hours, $\mathrm{V}$ has not been able to assess the learning results by himself, as well as recognize and rectify the learning mistakes of himself. However, $\mathrm{V}$ is a student who is eager to learn, explore, discover and especially loves Physics. The final score of Semester I, Physics of X is 7.2.

(3) Nguyen Phuong K, born on April 12, 2002 is a student with weak academic performance as assessed by the Physics teacher. $\mathrm{K}$ is a person who does not have self-awareness in learning, rarely completes assignments assigned by a teacher, does not identify the learning goals. The final score of Semester 1 of Physics of K is 4.1.

The results of monitoring the self-study competence of each student through the classes are as follows:

* First experimental hour: Teaching the lesson Refraction of Light

- In Activity 1, 2: Experiment with light refraction phenomenon. Through observation, notice that all 3 students pay close attention to the experiment, students $\mathrm{X}$ and $\mathrm{V}$ have a positive expression of thinking about the plan and conduct a good experiment when the teacher requires; student K does not have any activities he just sits quietly and does not cooperate with other students.

- Activity 3: Find out the refractive index of the environment. The teacher instructs the students to analyze the cases of the relative refractive index. Student X answers the teacher's questions but still shows embarrassment and is not confident to answer the questions. Student $\mathrm{X}$ states the relationship between absolute and relative refractive indices. Then Student V was called by the teacher to comment on the lesson for her friend, she just answered "probably right", did not dare to confirm whether X was right or wrong. For K, who has no idea, sitting indifferently with the lesson, sometimes he also talks privately.

At the end of the lesson, the teacher asks students to log in the E-learning Physics system to self-study and selfreview the content of the lesson they have just learned. Also students are asked to do exercises via the system.

After Lesson 3, students are given a questionnaire, the results are presented in Table 1:

With the first experimental lesson, $\mathrm{X}$ thinks that the lesson is interesting and interesting. Student V thinks that the lesson is normal; student $\mathrm{K}$ does not care about the lesson.

* Second empirical lesson: Teaching the lesson of Complete Table 1. Survey results after the first experimental lesson

\begin{tabular}{lccc}
\hline \multirow{2}{*}{ Survey contents } & \multicolumn{3}{c}{ Students' responses } \\
\cline { 2 - 4 } & Student X & Student V & Student K \\
\hline The lesson is very interesting & Yes & Normal & No \\
\hline I find it quite interesting & Yes & No & No \\
\hline I feel normal & No & No & No \\
\hline I feel boring & No & No & No \\
\hline
\end{tabular}
Reflection. Because the teacher has assigned the task of asking students to go home, visit the E-learning Physics page to preview the experiment on the total reflection phenomenon, so from the first activity, they do not get embarrassed. Student $\mathrm{X}$ is still timid but sometimes he also has an idea to contribute when conducting experiments. X conducts light from the air environment into the glass and makes a comment. Through experiments and presentations in class, we 
observed that V was very confident in proposing how to make two types of rays appear. Student K conducted the experiment with an initial incident angle of zero and then gradually increasing the angle of incidence, based on observation observations, K correctly answered the brightness of the two refracted and reflected rays. Surveying the positives of these 3 members through distributing questionnaires to 5 class members, the results are as follows:

Through observation and Table 2; 3, students are positive. Self-study at home, self-experimentation at home, it is indicated that students come to class with confidence and through monitoring shows that student $\mathrm{X}$ has had time for self-study interaction and has questions to discuss with friends and teachers on the forum of Table 2. Survey results after the second experimental lesson

\begin{tabular}{lccc}
\hline \multirow{2}{*}{ Survey contents } & \multicolumn{3}{c}{ Students' responses } \\
\cline { 2 - 4 } & Student X & Student V & Student K \\
\hline Very active discussion & 4 & 2 & 0 \\
\hline Quite actively discussing & 1 & 3 & 0 \\
\hline Normally no comments & 0 & 0 & 3 \\
\hline Few comments & 0 & 0 & 2 \\
\hline
\end{tabular}
Physics E-learning system.

\section{* Third experimental lesson: Teaching Prism lesson}

Teachers teach all lectures in the classroom with the support of drawings and simulations of lectures on E-learning Physics system. Students acquire knowledge and self-study prism exercises at home through textbooks, reference materials and electronic exercises system in physical E-learning system.

In the first activity of the lesson, the teacher shows the slide structure of the prism for students to observe the prism and introduces some prisms for students to see. Ask students to define the prism. After watching, students X and V boldly answered the question. Student $\mathrm{K}$ has been called by the teacher and confidently answered that the lens are defined; After that, the teacher asked another question about the refractive angle and refractive index of the prism, K could not answer. In the next activities, the teacher organized a guide for students to discuss in groups and orientation for students to answer the right conditions to have the ray on the AC side of the prism. Ask each group to appoint a group leader. Student $\mathrm{X}$ is assigned to be the leader of group 3 and has done a good job as a leader. Student V has actively discussed and searched with other members. Student K received the assignment and began researching and commenting with the group members.

Our results are that all three students are actively involved. However, only student $\mathrm{X}$ and $\mathrm{V}$ give correct results while student $\mathrm{K}$ gives incorrect results. When called up to answer the question, student $\mathrm{X}$ and $\mathrm{V}$ volunteered to speak, student $\mathrm{K}$ appeared timid.

Thus, up to the third period, students $\mathrm{X}$ and $\mathrm{V}$ are still highly appreciated by their group members, but student $\mathrm{K}$ has only one opinion of the group members who think that students actively discuss but there is still 01 member said that Student $\mathrm{K}$ has not yet contributed to the Table 3. Survey results after the third experimental lesson

\begin{tabular}{lccc}
\hline \multirow{2}{*}{ Survey contents } & \multicolumn{3}{c}{ Students' responses } \\
\cline { 2 - 4 } & Student X & Student V & Student K \\
\hline Very active discussion & 3 & 2 & 0 \\
\hline Quite actively discussing & 1 & 2 & 1 \\
\hline Normally no comments & 0 & 0 & 2 \\
\hline Few comments & 0 & 0 & 1 \\
\hline
\end{tabular}
group but with the above results it can be confirmed that the combined learning method has helped students develop their own self-learning ability.

In addition, through teacher observations, the development of some self-study competency components of students before and after the experimental process is as follows (Table 4):

Table 4. The development of some self-study competency components of students Tran Le X.

\begin{tabular}{|c|c|c|c|c|c|c|c|c|}
\hline \multirow{2}{*}{$\begin{array}{c}\text { Behavioral criteria of some } \\
\text { observable component competencies }\end{array}$} & \multicolumn{4}{|c|}{ Before educational experiment } & \multicolumn{4}{|c|}{ After educational experiment } \\
\hline & Weak & Medium & Good & Excellent & Weak & Medium & Good & Excellent \\
\hline Define subject goals & & & $\mathrm{X}$ & & & & & $\mathrm{x}$ \\
\hline Determine the learning task & & $\mathrm{x}$ & & & & & $\mathrm{X}$ & \\
\hline Execution time & & $\mathrm{X}$ & & & & $\mathrm{X}$ & & \\
\hline Learn planning goals & $\mathrm{X}$ & & & & & $\mathrm{x}$ & & \\
\hline Assess regularly & & $\mathrm{x}$ & & & & & & $\mathrm{x}$ \\
\hline Choose the form of self-study & & $\mathrm{x}$ & & & & & $\mathrm{X}$ & \\
\hline Self-work with learning materials & & $\mathrm{x}$ & & & & & $\mathrm{X}$ & \\
\hline Lecture listening and taking note skills & & $\mathrm{x}$ & & & & & $\mathrm{x}$ & \\
\hline Skills to detect and solve problems, & & & $\mathrm{X}$ & & & & & $\mathrm{X}$ \\
\hline
\end{tabular}


present questions about the subject

Coordinate learning methods $\mathrm{X}$

$\mathrm{X}$

Self-review, self-strengthen, test and evaluate skills

Apply knowledge to solve specific exercises

Self-evaluate results

Adjust your self-study plan

$\mathrm{X}$

$x$

$\mathrm{X}$

$\mathrm{X}$

$\mathrm{x}$

Table 5. The development of some self-study competency components of student Truong Le V.

\begin{tabular}{|c|c|c|c|c|c|c|c|c|}
\hline \multirow{2}{*}{$\begin{array}{c}\text { Behavioral criteria of some } \\
\text { observable component competencies }\end{array}$} & \multicolumn{4}{|c|}{ Before educational experiment } & \multicolumn{4}{|c|}{ After educational experiment } \\
\hline & Weak & Medium & Weak & Medium & Weak & Medium & Weak & Medium \\
\hline Define subject goals & & $\mathrm{x}$ & & & & & $\mathrm{x}$ & \\
\hline Determine the learning task & & $\mathrm{x}$ & & & & & $\mathrm{x}$ & \\
\hline Execution time & $\mathrm{X}$ & & & & & $\mathrm{X}$ & & \\
\hline Learn planning goals & $\mathrm{x}$ & & & & & $\mathrm{x}$ & & \\
\hline Assess regularly & & $\mathrm{x}$ & & & & & & $\mathrm{x}$ \\
\hline Choose the form of self-study & & $\mathrm{x}$ & & & & & $\mathrm{x}$ & \\
\hline Self-work with learning materials & $\mathrm{X}$ & & & & & $\mathrm{x}$ & & \\
\hline Lecture listening and taking note skills & & $\mathrm{x}$ & & & & $\mathrm{x}$ & & \\
\hline $\begin{array}{l}\text { Skills to detect and solve problems, } \\
\text { present questions about the subject }\end{array}$ & & $\mathrm{X}$ & & & & & $\mathrm{x}$ & \\
\hline Coordinate learning methods & $\mathrm{X}$ & & & & & $\mathrm{x}$ & & \\
\hline $\begin{array}{l}\text { Self-review, self-strengthen, test and } \\
\text { evaluate skills }\end{array}$ & & $\mathrm{X}$ & & & & & $\mathrm{x}$ & \\
\hline $\begin{array}{l}\text { Apply knowledge to solve specific } \\
\text { exercises }\end{array}$ & & $\mathrm{x}$ & & & & & $\mathrm{x}$ & \\
\hline Self-evaluate results & & $\mathrm{x}$ & & & & & $\mathrm{x}$ & \\
\hline Adjust your self-study plan & & $\mathrm{x}$ & & & & & $\mathrm{X}$ & \\
\hline
\end{tabular}

Table 6. The development of some self-study competency components of student Nguyen Phuong K.

\begin{tabular}{|c|c|c|c|c|c|c|c|c|}
\hline \multirow{2}{*}{$\begin{array}{c}\text { Behavioral criteria of some } \\
\text { observable component competencies }\end{array}$} & \multicolumn{4}{|c|}{ Before educational experiment } & \multicolumn{4}{|c|}{ After educational experiment } \\
\hline & Weak & Medium & Weak & Medium & Weak & Medium & Weak & Medium \\
\hline Define subject goals & & $\mathrm{X}$ & & & & & & \\
\hline Determine the learning task & $\mathrm{x}$ & & & & & $\mathrm{x}$ & & \\
\hline Execution time & $\mathrm{x}$ & & & & & $\mathrm{x}$ & & \\
\hline Learn planning goals & $\mathrm{x}$ & & & & & $\mathrm{x}$ & & \\
\hline Assess regularly & $\mathrm{x}$ & & & & & $\mathrm{x}$ & & \\
\hline Choose the form of self-study & $\mathrm{X}$ & & & & & $\mathrm{X}$ & & \\
\hline Self-work with learning materials & $\mathrm{X}$ & & & & & $\mathrm{X}$ & & \\
\hline Lecture listening and taking note skills & $\mathrm{x}$ & & & & & $\mathrm{x}$ & & \\
\hline $\begin{array}{l}\text { Skills to detect and solve problems, } \\
\text { present questions about the subject }\end{array}$ & & $\mathrm{X}$ & & & $\mathrm{x}$ & & & \\
\hline Coordinate learning methods & $\mathrm{x}$ & & & & & $\mathrm{x}$ & & \\
\hline $\begin{array}{l}\text { Self-review, self-strengthen, test and } \\
\text { evaluate skills }\end{array}$ & & $\mathrm{X}$ & & & $\mathrm{x}$ & & & \\
\hline $\begin{array}{l}\text { Apply knowledge to solve specific } \\
\text { exercises }\end{array}$ & $\mathrm{x}$ & & & & $\mathrm{x}$ & & & \\
\hline Self-evaluate results & $\mathrm{X}$ & & & & & $\mathrm{x}$ & & \\
\hline Adjust your self-study plan & $\mathrm{X}$ & & & & $\mathrm{x}$ & & & \\
\hline
\end{tabular}


The case study results show that the B-learning model helps develop the self-study competence of weak, fair and excellent students. Students who are weak after the initial self-study process also know how to identify plans for selfstudy, search documents and collaborate with you but do not know how to evaluate and adjust his/herself.

\section{DISCUSSION AND CONCULSION}

The results show that B-learning develops well the self-study competence of high school students, creating a motivation for learning thereby improving the quality of education and training. With the explosion of science and technology, teachers have provided many modern means and materials to support the teaching process. Especially for Physics, when many experiments cannot be done, are not eligible or guaranteed to be carried out in the laboratory, teachers instructing students to conduct virtual experiments, simulation experiments by themselves on the E-learning system will be an optimal plan to help students self-study but teachers still monitor, supervise and help. B-learning will be a popular form of learning in high schools in the near future to help teachers and students access new technologies during the industrial revolution 4.0. Thereby, improving the quality of teaching at high school level.

\section{REFERENCES}

Allan, B. (2018). E-learning and blended learning. In The No-Nonsense Guide to Training in Libraries (pp. 133-150). https://doi.org/10.29085/9781856049634.007

Alqarni, A. (2018). Blended Learning and Flipped Classroom Approaches. American Research Journal of Humanities and Social Sciences, 4(1), 1-6. https://doi.org/10.21694/2378-7031.18012

Barry J. Zimmerman. (1990). Goal Setting and Self-Efficacy During Self-Regulated Learning. Educational Psychologist, 25(1), 3-17. https://doi.org/10.1207/s15326985ep2501

Jang, J. S. R. (1992). Self-Learning Fuzzy Controllers Based on Temporal Back Propagation. IEEE Transactions on Neural Networks, 3(5), 714-723. https://doi.org/10.1109/72.159060

Le Hien Duong (2010). Forming and developing self-studying capacity for junior college Maths students. Vinh University.

Le Thanh Huy \& Nguyen Thi Bich Hoa (2018). Fostering self-study ability for students with the help of computers through classroom teaching "Light quantum" (Physics 12). Journal of Education, Special Vol. (6), 182-188.

Luong Viet Manh (2015). Forming and developing self-studying capacity for students in teaching Physics at Ethnic Preparatory School. Vinh University.

Nguyen Van Hien (2016). Developing self-study capacity for pedagogical students through E-learning. Science Magazine of Ho Chi Minh City University of Education, 4 (82), 9-13. Retrieved from http://hvtc.edu.vn/tabid/558/catid/ 143/id/18355/Mot-so-giai-phap-de-phat-trien-van-hoa-doc-cho-sinh-vien-cac-truong-dai-hoc/Default.aspx

Setyaningrum, W. (2019). Self-regulated learning in blended learning approach. Journal of Physics: Conference Series, 1320, 012089. https://doi.org/10.1088/1742-6596/1320/1/012089

Tran Duc Khoan (2016). Building and using self-guided learning materials according to the module "Electricity" in General Physics contributes to fostering self-study capacity for technical university students. Vinh University.

Tran Trung \& Nguyen Van Hong (2011). Application of information technology to teaching mathematics in high schools. Vietnam Communication Publishing House.

Trinh Quoc Lap (2003). Self-Studying in Vietnam. Journal of Science, Can Tho University, 169-175.

Trinh Thi Phuong Thao (2015). Exploiting a number of mobile applications to support student grade 12 to study Math by themselves. Vietnam Academy of Educational Sciences.

Welker, J., \& Berardino, L. (2005). Blended Learning: Understanding the Middle Ground between Traditional Classroom and Fully Online Instruction. Journal of Educational Technology Systems, 34(1), 33-55. https://doi.org/10.2190/67fx-b7p8-pyux-tdup

Yang, H. H., MacLeod, J., Yang, H. H., \& MacLeod, J. (2019). Blended Learning in Teacher Education. Oxford Research Encyclopedia of Education. https://doi.org/10.1093/acrefore/9780190264093.013.276

Yoda, H., Miyatake, T., \& Matsushima, H. (1991). A kinematic model with a self-learning capability of a series of motions based on instinctive incentive. Systems and Computers in Japan, 22(6), 77-86. https://doi.org/10.1002/scj.4690220608 